\title{
The Late Quaternary history of northern Eurasia and the adjacent Arctic Ocean: an introduction to QUEEN
}

\author{
Jörn Thiede (AWI) and Henning A. Bauch (GEOMAR)
}

\section{The Motive for QUEEN}

The European climate has been subject to rapid and dramatic changes during the latest geologic past, mainly because of the instability and variability of the regional extension of the temperate climatic zones into very high northern latitudes, in particular over northwestern Europe and the adjacent ocean basin (Fig. 1).

From reconstructions of the Late Cenozoic climatic history of this area (CLIMAP 1976) it is well known that peak interglacial climates when this anomalyexisted were rare exceptions from the more normal glacial conditions when the extension of the Gulf Stream current system did not enter the Nonvegian- Greenland Sea, thus generating patterns of atmospheric and oceanic circulation which resulted in a substantially colder climate over Europe than we have today. The programme Quaternary Environments of the Eurasian North (QUEEN), sponsored by the European Science Foundation, atempts to correlate well established and well dated records of the Late Quaternary paleoen- vironmental history of the northern and eastern segments of this anomaly which are particularly poorly known, but where rapid progress has been achieved over the past years (e.g. Kassens et al. 1999).

Northern Europe probably experienced the most dramatic and fastest climatic changes over the youngest geological past (Andersen \& Borns 1994), as compared to other terrestrial environments of this Earth. Many studies indicate that it may also be subject to substantial changes in the future (Lozán et al. 1998), regardless of whether or not such changes are triggered by natural climatic variability or the impact of man on the global environment (GLOBAL CHANGE). To safeguard the future not only of the European populations, but of mankind itself, it is therefore highly important to understand the past climatic history of the region. Such studies will help to gain some insight into the "memory" of the climate over the northern hemisphere which led to the development of the modem climate, but potentially also to establish a scientific base for climate prognosis.

The most prominent expressions of the properties of the Late Quaternary climates over the northern hemi- sphere are the waxing and waning of large glacial ice sheets on the circum-Arctic continents. The areas they covered are, by virtue of their 
erosional effects, not well suited for the reconstruction of their histories, whereas their terrestrial fringes provide a detailed record of the deglacial withdrawal of the ice margins from their last glacial maximum until they disappeared completely during the Holocene. While the western European record of this history can be considered relatively well known (see also Fig. 1), the northern, southern and eastern extensions of these ice sheets and the regional coherence of the individual ice domes is relatively little known (cf. Svendsen et al. 1999). QUEEN attempts to synthesize the new knowledge gained from the many ongoing projects in the area of interest and to stimulate new investigations in areas which may hold clues for a better understanding of this history.

Finally, terrestrial and shelf sea records are, in all probability, either stratigraphically incomplete because of the erosion of landsurfaces and of eustatic as well as isostatic sea level changes, or they are products of local rather than global processes (such as those found, for example, in limnic sediment sequences). In combina- tion with new samples and data obtained from the deep Arctic ocean sediments in recent years (Spielhagen et al. 1997), there are now available excellent and uninterrupted records providing insight into the paleoenvironmental history of northern Eurasia during the last two glacial cycles, which can then be related to the Late Quaternary record of GLOBAL CHANGE.

\section{Progress in QUEEN}

The papers published in this volume are the partial outcome of presentations given at the first QUEEN workshop in Strasbourg, France (Nov. 29 to Dec. 2, 1996), but since then new data and results have been incorporated. They report on ongoing projects which in part were initiated before the establishment of QUEEN. They cannot provide a complete coverage of the QUEEN topics, neither with respect to time scales nor to regions, but the intention of the joint publication of these papers in one issue is to highlight the significance of the paleoenvironment of northern Eurasia and of the adjacent Arctic Ocean.

The big enigma of the QUEEN region is the question of the northern and eastern extension of the glacial ice sheets. Substantial efforts are therefore invested in trying to map and date such ice margins, or to use indirect evidence such the isostatic response of coast- lines to the deglacial retreat of ice sheets. True local, paleoclimatic case studies are provided by reconstructions of the vegetation cover from the pollen records of limnic sediment sequences, which can be used to document interglacial time spans in repeatedly glaciated areas, such as in northern Finland and Karelia, or of glacial time spans when the sedimentary basins were located outside the margin of the last glacial maximum, such as the records from Taymyr Peninsula.

The Eurasian Arctic marginal seas and the adjacent ocean basin represent depositional environments with their own characteristics. However, they are closely linked to the history of the continental hinterland because the terrestrial minerogenic and biogenic sediment components are remnants of the mechanical and chemical erosion affecting these areas, depending upon their climatic regime, and witnesses of the habitats which existed there. The shelf seafloors, with their occurrences of submarine permafrost, have peculiar properties which are not found anywhere else. 
Finally, the deep Arctic Ocean deposits are the result of the transport processes of terrestrial sediment components to the deep sea (as suspended material in river and sea water as well as in sea ice, or as ice-rafted material) via the shelf seas, and of the paleoceano- graphic properties of the ocean water masses as reflected in the composition of shells and skeletal parts of the oceanic plankton. The Arctic Ocean is almost completely surrounded by continents, with the result that its ocean waters are modified at varying degrees by the riverine fresh water influx from the adjacent land masses (Stein et al. 1998).

\section{Perspectives of QUEEN}

The papers of this volume cannot cover all of the scientific facettes of the QUEEN problems and region, but as the outcome from QUEEN'S first workshop they offer an idea of the fast progress which is now possible now that the northern Eurasian land areas, shelf seas and adjacent ocean basins are open for scientific research. This is not only the result of changing political winds, but also of the technical possibilities of carrying out expeditions in these extreme environments and of the scientific awareness of the importance of these areas for an understanding of globally important processes of climatic change. The European research institutions both in and outside Russia are driven by the fact that these areas, among others, harbour the most important data for a better understanding of past and future climate history over Europe.

In 1997 and 1998 QUEEN teams have organized new field work with important new discoveries which will allow further progress of our understanding of the Late Quaternary history of the paleoenvironment of the Eurasian North. They will report about their activities in short descriptions of the fieldwork carried out, to be published in the LUNDQUA Reports and in the proceedings of future QUEEN workshops.

Acknowledgements.- In early 1996, the European Science Foundation (ESF) established QUEEN (Quaternary Environments of the Eurasian North) as one of its 'a la carte' programmes under the auspices of its LESC (Life and Environmental Sciences Committee). The main aim of this programme was to facilitate the exchange of new discoveries of the Late Quaternary paleoenvironmental history in a region which is of eminent importance for understanding European climate history, with a focus on an area which was accessible to modem paleoenvironmental research only under circumstances of great difficulty. Major progress in studying the QUEEN region can now be observed, mainly because of the establishment of a number of bilateral projects between research institutions in Russia and in western countries. Through the QUEEN programme, ESF is facilitating the exchange of new data and knowledge, as documented by the papers of this volume. The authors and editors of the papers of this volume are deeply indebted to ESF for supporting QUEEN and to all external referees for making their time freely available to improve the quality of the published papers in this issue of Boreas. 
References

Andersen, B. G. \& Borns, H. W. J. 1994: The ice age world. 208 pp. Scandinavian University Press, Oslo.

Baumann, K. H., Lackschewitz, K. S., Mangerud, J., Spielhagen, R. F., Wolf-Welling, T. C. W., Henrich, R. \& Kassens, H. 1995: Reflections of Scandinavian ice sheet fluctuations in Norwegian sea sediments during the past 150000 years. Quaternary Research 43, 185-197.

CLIMAP, P. M. 1976: The surface of the ice-age earth. Science 191, 1131-1137.

Kassens, H., Bauch, H. A., Dmitrenko, I., Eicken, H., Hubberten, H.-W., Melles, M., Thiede, J. \& Timokhov, L. (eds.) 1999 Land-Ocean Systems in the Siberian Arctic: Dynamics and History. 692 pp. Springer, New York.

Lozán, J. L., GraßI, H. \& Hupfer, P. (eds.) 1998: Warnsignal Klima - Das Klima des 21. Jahrhunderts. 463 pp. Wissenschaftliche Auswertungen, Hamburg.

Spielhagen, R. F., Bonani, G., Eisenhauer, A., Frank, M., Frederichs, T., Kassens, H., Kubik, P. W., Mangini, A., Nørgaard-Pedersen, N., Nowaczyk, N. R., Schaper, S., Stein, R., Thiede, J., Tiedemann, R. \& Wahsner, M. 1997: Arctic Ocean evidence for Late Quaternary initiation of northern Eurasian ice sheets. Geology 25,738-786.

Stein, R. (ed.) 1998: Arctic Paleo-River Discharge (APARD): A new research programme of the Arctic Ocean Science Board (AOSB). Reports on Polar Research 279, 1-128.

Svendsen, J. I., Astakhov, V. I., Bolshiyanov, D. Yu.,Demidov, I., Dowdeswell, J. A., Gataullin, V., Hjort, C., Hubberten, H. W., Larsen, E., Mangerud, J.. Melles, M., Moller, P., Saarnisto, M. \& Siegert, M. J. 1999: Maximum extent of the Eurasian ice sheets in the Barents and Kara Sea region during the Weichselian. Boreas 28, 234-242.

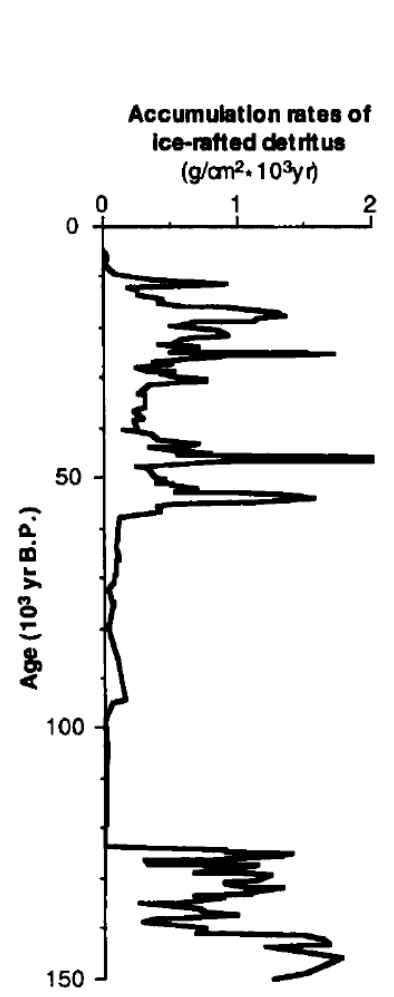

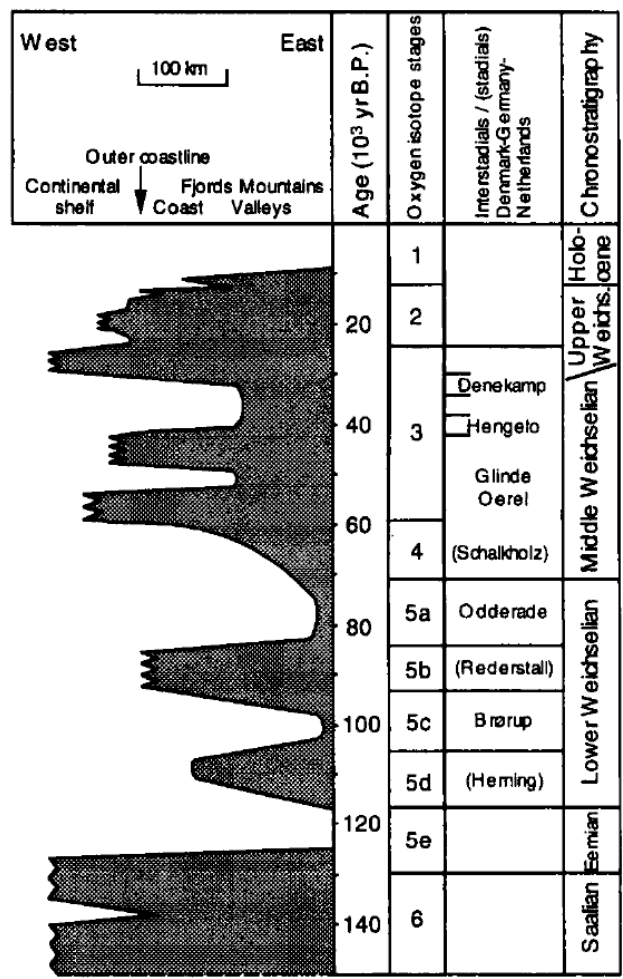

Fig. 1. Fluctuations of the western Fennoscandian ice shield and the deposition of ice-rafted detritus in the adjacent basin (from Baumann et al. 1995). 